TI 2002-095/3

Tinbergen Institute Discussion Paper

\title{
Environmental Tax Reform and Double Dividend
}

Roberto Patuelli

Eric Pels²

Peter Nijkamp 2,3

${ }^{1}$ Ravenna, Italy, 2 Faculty of Economics and Business Administration, Vrije Universiteit Amsterdam,

3 Tinbergen Institute. 
Tinbergen Institute

The Tinbergen Institute is the institute for economic research of the Erasmus Universiteit Rotterdam, Universiteit van Amsterdam and

Vrije Universiteit Amsterdam.

Tinbergen I nstitute Amsterdam

Keizersgracht 482

1017 EG Amsterdam

The Netherlands

Tel.: +31.(0)20.5513500

Fax: $\quad+31 .(0) 20.5513555$

Tinbergen Institute Rotterdam

Burg. Oudlaan 50

3062 PA Rotterdam

The Netherlands

Tel.: $\quad+31 .(0) 10.4088900$

Fax: $\quad+31 .(0) 10.4089031$

Most TI discussion papers can be downloaded at

http://www.tinbergen.nl 


\title{
Environmental Tax Reform and Double Dividend: A Meta-Analytic Performance Assessment
}

\author{
Roberto Patuelli ${ }^{1}$ Eric Pels ${ }^{2} \quad$ Peter Nijkamp $^{2}$ \\ ${ }^{1}$ via Mangagnina 33/A, 48100 Ravenna (Italy); email: patuelli@tin.it \\ ${ }^{2}$ Free University, Department of Spatial Economics \\ De Boelelaan 1105, 1081 HV Amsterdam, The Netherlands
}

\begin{abstract}
In this paper we offer a meta-analysis approach to (simulation) studies on environmental tax reform (ETR). The underlying studies look both at environmental effects (e.g. reduction in $\mathrm{CO}_{2}$ emission) and economic effects (e.g. change in gross domestic product) following such a tax reform. The statistical results suggest that the tax type, the recycling-policy and the economic model used in the simulations are all of influence on the chance a double dividend can be obtained. The results are however not entirely conclusive regarding the question which combination of policies and models will lead to a higher double dividend. Our metaanalytic experiment also shows that the specific definition of the double dividend (partly) determines the outcome. These findings should be taken into consideration applying an ETR, to prevent a situation where ETR is rejected or accepted solely due to characteristics of the underlying simulation study rather than the intrinsic ETR itself.
\end{abstract}

\section{Introduction}

Environmental Tax Reform (ETR) has in recent years become a much debated issue in environmental policy (see e.g. Bosquet, 2000, for an extensive overview). It is based on the introduction of so-called green taxes and the refund of the obtained revenues through reductions of distortionary taxes. This issue is nowadays a heated policy subject; it is co-determined by the rise in the politicians' understanding of complex environmental problems like multi-source pollution caused by industries and households, the increasing energy needs of several countries and the uncontrolled exploitation of the earth's natural resources. The theoretical discussion on ETR focuses on the double dividend (the joint occurrence of an environmental and economic improvement), which, although possible, may not be likely to occur (see e.g. Bosquet, 2000). The empirical suggests that under certain conditions ETR can 
lead to a double dividend (Bosquet, 2000). The discussion surrounding (the expected effects of) ETR calls for a meta-analysis, where policy analysis itself is analysed (see van den Bergh et al. (1997) for an extensive discussion of meta-analysis in environmental economics).

ETR originates from the consideration that there is generally a lack of effective environmental policy in most of the industrialised or emerging countries. It is a sine qua non that these countries at least stabilise their emissions of $\mathrm{CO}_{2}$ and - in the opinion of the Intergovernmental Panel on Climate Change (IPCC) - reduce them even by 60-80 percent "immediately" (see e.g. Barker et al. 1993).

In this paper we will consider the key factors that influence the performance of ETR. Clearly, different types of environmental policies can be distinguished and implemented. Carbon taxes or energy taxes, for example, can be used on the economic efficiency side, while the usual (and most often studied) instrument of financial recycling is one that aims to reduce labour costs. The aim is to offer a quantitative comparative study of the estimated performance of ETR instruments, as far as they can be traced from a large set of applied studies. The statistical instruments employed in our study are based on meta-analytical principles.

In the next section we will discuss the main characteristics of ETR and of double dividend (a mechanism which aims to provide both environmental and economic benefits). Section 3 will then present several comparisons of principal features of the ETR studies included in our database. This overview will next be followed by a statistical meta-analytical examination of the critical factors influencing the ETR's environmental and economic results as far as these can be identified from our database. We will then search for statistical evidence that identifies which main factors are the determining drivers. Finally, some concluding remarks will be offered, while also directions for future research will be suggested.

\section{Environmental Tax Reform and Double Dividend}

ETR has in the past decade become an important vehicle in environmental policy. For example, in 1997 the European Commission revised the Community framework on energy products taxation, proposing a new ecotax policy (European Commission, 1997a,b; Jansen and Klaassen, 2000), since the minimum excises on mineral oils from the previous directive $(92 / 82 / \mathrm{EEC})$ were no longer sufficient according to the results 
of recent studies. Furthermore, the May 1995 proposal on $\mathrm{CO}_{2}$ and energy taxation (European Commission, 1995) did not find sufficient support among European politicians, while the European Commission wanted to stimulate member states to shift taxes away from personal income and labour cost toward environmental instruments.

The ETR mechanism consists of recycling revenues from environmental taxes - on carbon products, energy consumption or use of natural resources - in order to reduce taxes on other phases of the production process, usually making labour less expensive (for an in-depth treatment of the trade-off between various production factors we refer to Mabey and Nixon, 1997). Alternatively, the revenues might be employed to reduce other distortionary taxes on the "good" part of the economic process (like personal income taxes or social security contributions). Bossier and Bréchet (1995) suggest that the introduction of broader policy strategies, which include regulatory measures and technological research, result in more efficient energy usage.

The theoretical, environmental-economic policy literature interprets the revenue recycling mostly as a reduction of social security contributions (SSC) or personal income taxes (PIT), but other forms of financial recycling are also possible, like lump sum transfers to households/industries (consisting of recycling the revenues to households or to the industries in the form of "una-tantum" gratifications) or interventions in corporate profit taxes (CPT) or value added tax (VAT).

Recycling tax revenues may be a very promising and useful policy tool, since various taxes (such as CPT or VAT) are already high, especially in Europe. Raising these taxes even further, without the right counterbalance (or a proper form of recycling), might be economically damaging, and would not be readily accepted by many politicians and by the citizenship at large. Furthermore, ETR is supposed to be neutral, leaving the total tax revenue unchanged.

The neutrality of ETR depends on the share of tax revenues that are recycled. Only a few countries that have embarked on ETR policies, like Finland, Sweden and Germany, have decided to employ a revenue-negative tax - reducing total income - , but ETR has usually been applied in a neutral way. It should also be noted here that recycling environmental tax revenues does not necessarily imply neutrality for the balance of payments (Barker et al., 1993). Otherwise, if the government were to keep the revenues from green taxes without recycling them within the system, an economic 
depression would be likely to take place. The extent of the new tax burden after the ETR implementation can be estimated by considering the pre-existing tax rate on the taxed factor and the decrease in its demand (de Mooij and Bovenberg, 1998).

As of the year 2000, eight countries have introduced explicit ETR policies with different levels of intensity (Bosquet, 2000). For example, in 1999 Italy introduced a soft reform that cumulates less than $1 \%$ of the total tax income, while Denmark has a system of ecological taxes, introduced in 1994, that is balanced by reductions in SSC and PIT, and that amounts to more than $6 \%$ of the total revenue.

The unwillingness of several countries to apply green taxation reforms on a broader scale is inter alia based on the fear of a reduction in the competitiveness of their (national) industries, especially those that consume large amounts of energy, like the iron and steel industries, and the producers of paper, cement and fossil fuels (Gee, 1997). This problem does not necessarily occur in reality, in particular because of the cost advantage given by the labour cost reduction (Bossier and Bréchet, 1995). In any case, financial support for energy-intensive firms could be introduced in the form of subsidies or refunds, although this would probably weaken the effectiveness of the ETR.

Although it ought to be recognised that ETR could damage the economy, economic theory suggests that ETR might bring about a double dividend. This is based on a double tax objective, and combines a cleaner environment (the first dividend) with an increase in employment or Gross Domestic Production (GDP) (the second dividend). Bovenberg and Van der Ploeg (1993) offer the following definition of double dividend, which we will use later on in our statistical analysis: The hypothesis that higher pollution taxes associated with more environmental concern would not only improve the environment but also boost employment (and hence the tax base), we call the "double dividend" hypothesis. This is not to say that the double dividend is limited to the tax base (GDP could also be included). Barker (1997) notes that also macroeconomic effects (of ETR) can be expected, because of the higher salaries and expenses generated by a hypothetical increase in employment.

A double dividend could be obtained through the effect of lower taxes on work or, more generally, on the economic system. The combination of taxes on pollution (or energy use) and lower taxes on labour should lessen the relative price of labour inputs (or human capital) compared to energy. Basically, the chances of obtaining a double 
dividend depend on the balance between economic losses caused by the ecological taxes and the benefits accruing from the revenue recycling. Gee (1997) lists several factors that may influence the introduction of a green taxation policy. Such factors could include the use of broader policy packages and large amounts of public/political support.

In addition, the efficiency of ETR can be examined in different ways. A costbenefit analysis, carried out by Morris et al. (1999), showed that an ETR consisting of soft polluting taxes and labour costs recycling did indeed provide a significantly positive benefit-cost ratio, which may decline, however, in the presence of more restrictive environmental taxation.

In contrast, ETR may also generate secondary effects, such as an inflationary spiral (Bossier and Bréchet, 1995). This may be due to increases in the price of production factors, which may induce higher consumer prices. On the one hand, firms that do not pay the (environmental) tax could benefit from their situation and "improve their competitive position in relation to those industries which do pay" (Barker et al., 1993, p. 300). On the other hand, this advantage could be a "survival of the cleanest" type of process, which could be particularly favourable for the environment.

Despite the abundance of literature, there is surprisingly little evidence of the existence of a double dividend, neither in the theoretical nor the empirical literature. Factors that may determine whether or not a double dividend would be obtained include the type of recycling, the production factors employed, labour elasticities, employment market inefficiencies (i.e., pre-existing labour taxes) and the treatment of international and financial flows (Jansen and Klaassen, 2000). A possible cause of "failure" (i.e., the absence of a double dividend) could instead be "announcement effects" (Wendner, 2001). Such announcement effects occur when, due to anticipation, consumption and investment are already distorted, before the change in economic variables produced by an ETR actually takes place. Moreover, Carraro et al. (1996) find that, in the long run, gains in employment might occur despite decreases in environmental dividends, due to changes in the composition of the aggregate demand. Their hypothesis is that the unions' negotiating strength affects the possibility of gains in employment, because of increasing net wages.

Bosquet (2000) extensively reviewed a number of (simulation) studies on the predicted effect of ETR. The main conclusion was that "reductions in $\mathrm{CO}_{2}$-emissions 
may be significant, marginal gains in employment and marginal gains or losses in activity may be recorded in the short- to medium-term, and investments decrease and prices increase moderately". The following sections will further analyse previously undertaken applied research on ETR, investigating the possibilities for creating a double dividend. The simulation study results can be classified into different groups based on various model and /or study characteristics, such as region of interest, type of model, type of tax recycling etc. It will then be tested whether the vector of "effect means" is statistically equal across groups. If not, then possible systematic differences in study means will be analysed. The next section will present the characteristics and results of the set of available ETR studies, while in Section 4 several statistical metaanalytical analyses will be presented which aim to find significant evidence for the potential successfulness of certain ETR strategies.

\section{Database Description}

\subsection{The Available Data}

A great variety of applied (simulation) studies on estimated ETR impacts have been published in recent years. Our aim is to derive by means of comparative analysis some general findings from these studies. This section will briefly present common results from the collected studies. Later on we will investigate whether and how the results change when we categorise the studies according to several moderator and methodological characteristics.

The available database is composed of 191 simulations, belonging to 61 studies $^{1}$, which can be grouped according to, for example, the type of economic model used, the length of the simulation period employed and the type of environmental policies considered.

Since most of the studies comprise more than one simulation, we have chosen to use an infra-study means in our first attempt at describing the database. Since there are on average approximately 3 simulations per study, this data reduction is likely to bring about some loss of information, but it will probably allow us to avoid repetitive results from simulations belonging to the same study. Later in this paper all the simulations

\footnotetext{
${ }^{1}$ A set of studies collected by Bosquet $(2000,2001)$ was later updated with the inclusion of additional studies.
} 
will be used for our statistical analyses, since only a smaller number of cases are available for our meta-analytical study.

The variables - expressed in percentage variation from each study's baseline scenario - chosen for the comparative analysis are:

- $\mathrm{CO}_{2}$ emissions

- Employment

- GDP (Gross Domestic Product)

- Firms' investments

- Consumers' price level

The average results from the 61 studies show at first glance a noticeable characteristic (see Table 1): the average $\mathrm{CO}_{2}$ emission reduction, which is around $10 \%$, is in fact much larger than for the other variables. This difference suggests immediately that, despite the importance attached to the economic aspect of ETR, an ETR policy is more efficient on the environmental side than on the economic side. At the same time, it is clear that it is possible to improve the environment with a low or negligible variation in the economic sector.

Table 1 - Average results

\begin{tabular}{cccccc}
\hline & $\mathrm{CO}_{2}$ Emission & Employment & GDP & $\begin{array}{c}\text { Firms' } \\
\text { Investments }\end{array}$ & $\begin{array}{c}\text { Consumers } \\
\text { Prices }\end{array}$ \\
\hline $\begin{array}{c}\text { Average } \\
\begin{array}{c}\text { Variation } \\
\text { Standard Error }\end{array}\end{array}$ & -9.70 & 0.44 & -0.05 & -0.23 & 1.18 \\
\hline
\end{tabular}

One explanation for the difference in the policy performance between and the economic variables may be the economic structure of the energy-intensive industries, which would be heavily influenced by an energy tax. In fact, these industries usually employ a small number of people compared to other, more labour-intensive industries (Bosquet, 2000). Clearly, if we would define the second dividend as a gain on the employment side, we can still affirm that our data suggest that the occurrence of a double dividend is feasible.

All variables in Table 1 have considerable standard errors, which means that we may expect large confidence intervals for our statistical analyses. This high variability is due to the heterogeneity of the studies and to the artificial variability caused by the simulation nature of the results. In other words, the results are not likely to be 
normally distributed. Discordance can also be observed in the results, since employment and the GDP show variations of different sign. Furthermore, the variation in employment is bigger than in GDP, which contradicts the general tendency in Europe $^{2}$ for economic growth combined with relatively small increases in employment (Barker and Köhler, 1998).

Small effects can also be observed in investments, which show nearly null variation, although the negative sign persistently appears throughout the data under examination. This negative effect is probably due to the increase in the price of energy, to which capital investment is strictly tied (Bosquet, 2000). This forms also an explanation for the disappointing estimated results on GDP. It is plausible that the rate of capital accumulation directly affects economic growth (Wendner, 2001). It is noteworthy that a different conclusion however, is drawn by Kuper (1996, p. 149), who claims that "energy and capital are better substitutes for each other than are labour and energy...especially for the chemical sector and the metal manufacturing industries".

Contrasting results can be seen for consumers' prices. It will be shown later on that nearly each simulation shows a higher level of prices compared to the situation without ETR. The reason for this inflationary spiral is an increase in the price of energy, which forces firms - especially the energy-intensive ones - to raise the prices of their products, thus creating a major expense for households. ${ }^{3}$

In the next sections we will investigate the existence of potential differences in performance results according to different characteristics or features of the studies considered. We will therefore classify the available simulations - using infra-study means - in order to compare and explain the results from sub-classes of studies belonging to our database (i.e., we will in particular observe the differences between short/medium- and long-term simulations). This in depth consideration of the data may permit us to distinguish policy failures and factors that may induce a success in ETR.

The studies - which were divided according to infra-study characteristics - were classified into different groups based on the following criteria:

- Europe vs. Rest of the world

\footnotetext{
${ }^{2}$ The studies collected are mostly addressing European countries.
} 
- Mediterranean countries vs. Northern European countries

- Short/medium-term vs. Long-term

- European Community tax vs. other taxes

- Social security contributions recycling vs. other ways of recycling

- Publication bias (by addressing differences between results found in refereed articles and those found in other kinds of publications, plus those found in unpublished works)

\subsection{Subgroup Comparisons}

The implementation of ETR has caused varying and heterogeneous performance effects worldwide. Consequently, policies applied in different regions may produce different results, depending on site-specific conditions and on various moderator variables. In order to verify this, the database was split into two sets of results, one comprising studies on European countries and one comprising studies on the rest of the world (see Figure 1). Furthermore, a second subdivision allows us to compare Mediterranean countries - like Spain or Italy - with Northern European countries, a group comprising Germany, The Netherlands and Scandinavia (see Figure 2).

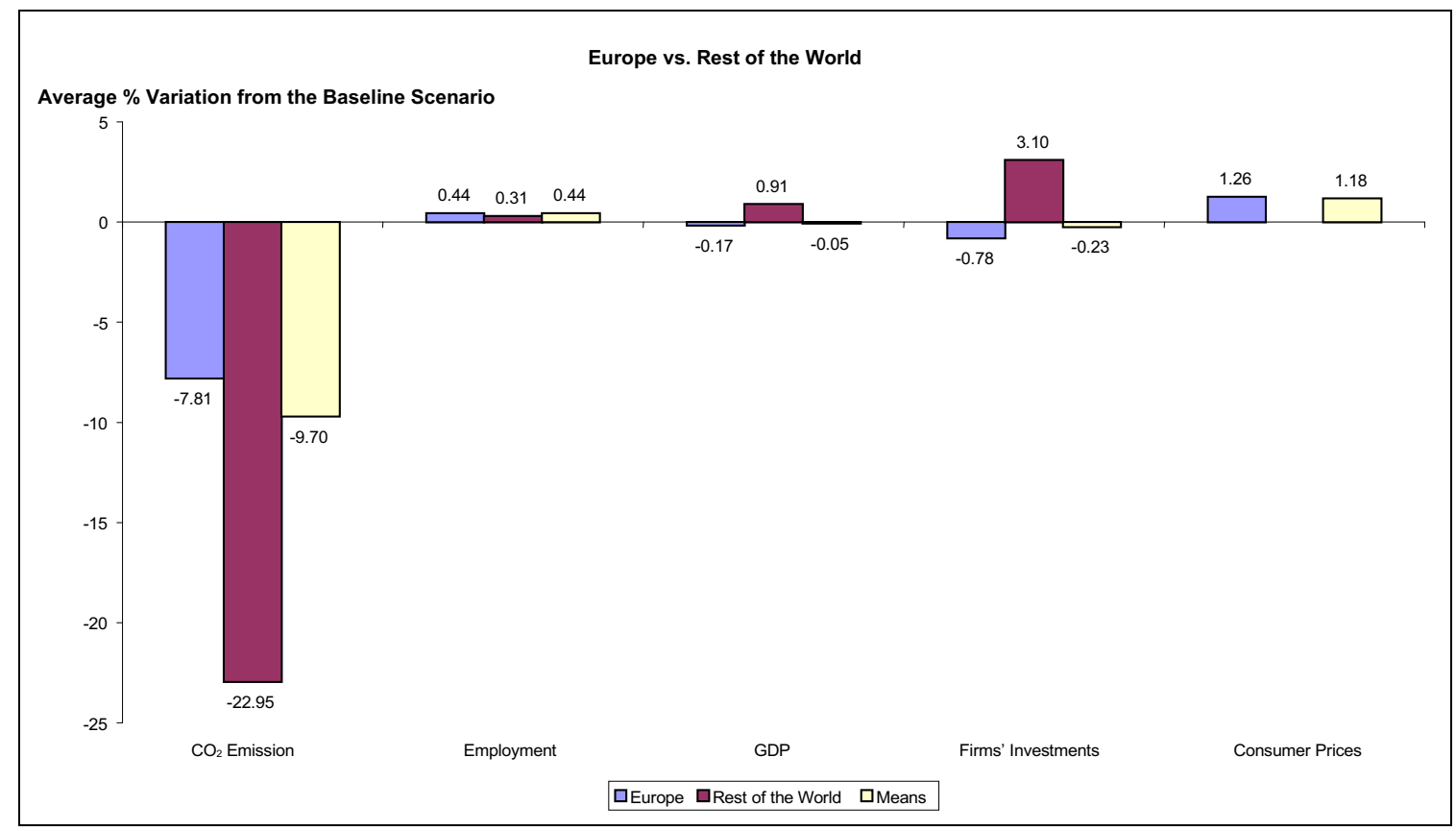

Figure 1 -Europe vs. Rest of the world

\footnotetext{
${ }^{3}$ An energy tax would in fact obtain approximately half of its revenues from households, because of the domestic use of energy.
} 
The first striking differences in Figures 1 and 2 are the heterogeneous results on the environmental side of ETR. In fact, the amounts of variation in the $\mathrm{CO}_{2}$ emission are very different. The studies can be subdivided into two groups that we will call optimistic and modest. In the first class, the authors hypothesise that there will be drastic reductions in emissions, while the second class presents better founded hypotheses on a decrease. It should also be noted that in several studies the emission reduction levels are chosen a priori and that the number of studies on non-European countries is low. Also, within the studies on European zones, most of the simulations are focused on Nordic countries.

Apart from these considerations, it is noteworthy that the results for the "Rest of the world" group are rather optimistic. In fact, both employment and GDP variations are positive, with a significant increase for investments as well, although this is mostly due to an outlier (12.6\%) among the study results.

In Figure 2 we can observe that different scales of environmental improvement produce similar economic results: the results on employment and GDP for Mediterranean and Nordic countries are quite similar.

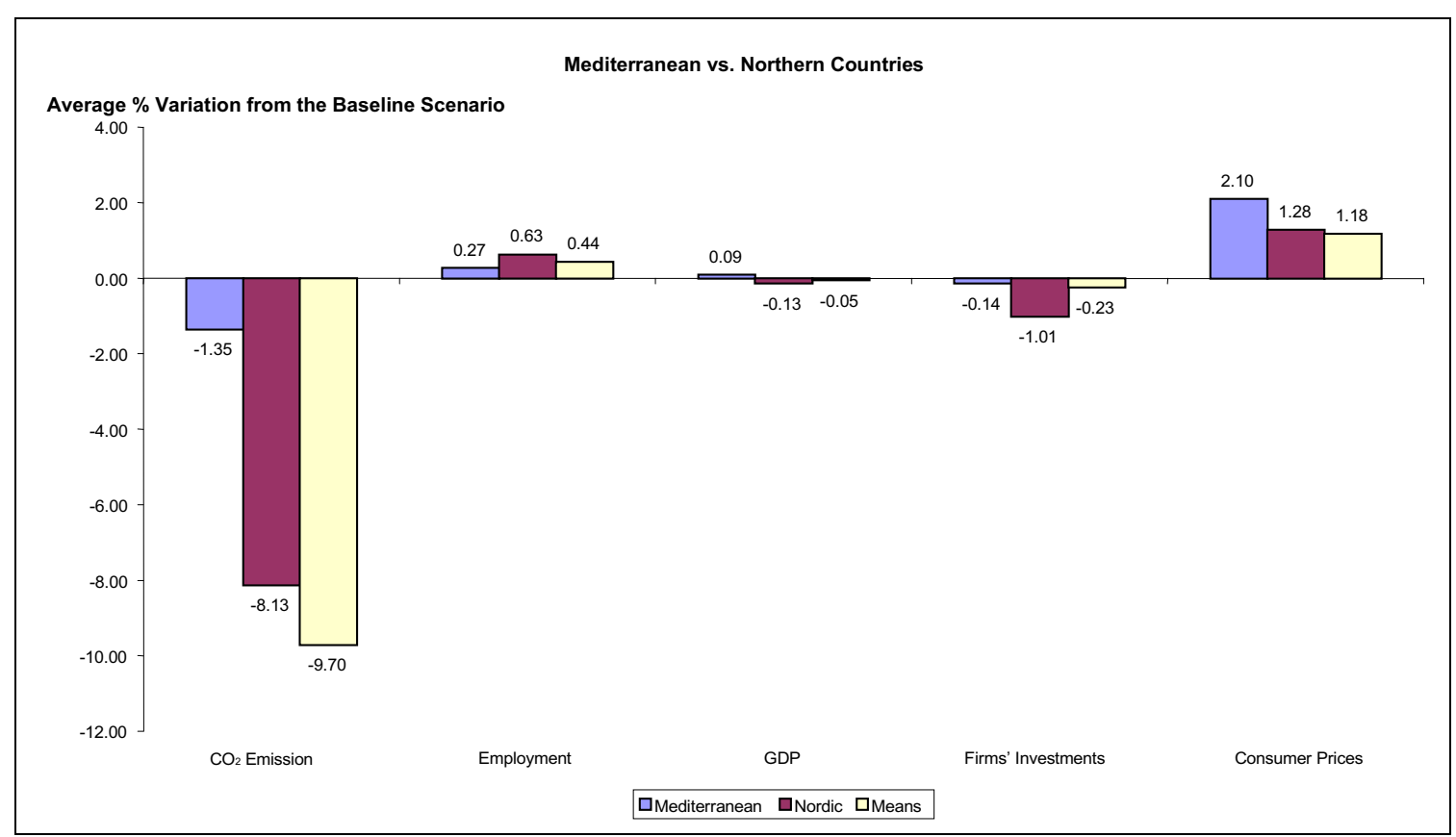

Figure 2 - Mediterranean countries vs. Nordic countries.

These results show environmental and employment benefits. Consequently, the question is: will they last over time? Several authors point out that in the long run the economic benefits tend to disappear (Bosquet, 2000). 
In order to test this conclusion, we have divided the studies into two categories: the first one contains simulations for time periods smaller than ten years (we consider these short/medium-term), while studies with longer time periods of implementation were placed in the second category (we call these long-term studies).

The results from these sub-groups display some important features (see Figure 3). Firstly, a difference in the environmental results of short/medium- and long-term simulations is evident. It is likely that this is due to the time frame necessary for firms to adjust their plants and to technological progress, which permits the introduction of environmentally cleaner equipment. Thanks to these factors, the long-term benefits for the environment appear to double. Another significant finding is the evidence of the permanence of a double dividend, since the results for the two different time frames are similar. The same happens for GDP, which always remains very close to its level in the base scenario simulations. On the investment side, the graph shows, in the long term, an end to the depression caused by the new taxes, while the prices continue to be higher than in the baseline scenarios for both periods. Since the only aim of energy taxes is a change in relative prices, it remains to be considered how we can avoid what seems like a permanent increase in price levels.

Kuper (1996) has analysed how much time the system will take to find a new equilibrium and "how" this will come about. From the results presented here, it seems the economy will react well to the new taxes, without considerable deviation, either in the short-term or in the long-term. The effect on the $\mathrm{CO}_{2}$ emission is, however, stronger in the long run.

Researchers investigating ETR have shown much interest in the way benefits can be obtained. The European Commission proposed tax of 1992 is an example of what is surely the most studied form of carbon/energy tax ${ }^{4}$. This tax policy represents a focal point in the brief history of ETR. Since 1992 a large number of studies have been undertaken - often with EC approval - in order to test this proposal or to consider it as a starting point for different policy considerations (Barker et al. 1993; Carraro et al., 1995). We will therefore, compare studies examining the EC tax with

\footnotetext{
${ }^{4}$ The EC tax is, in fact, a combination of charges on emissions and energy materials, like fuels and electricity. The revenues of these taxes are then employed in reducing labour costs. The total balance of the policy is supposed to be budget neutral.
} 
studies using "other forms". The aim is to verify whether the EC policy generates likely greater benefits than the other policies. ${ }^{6}$

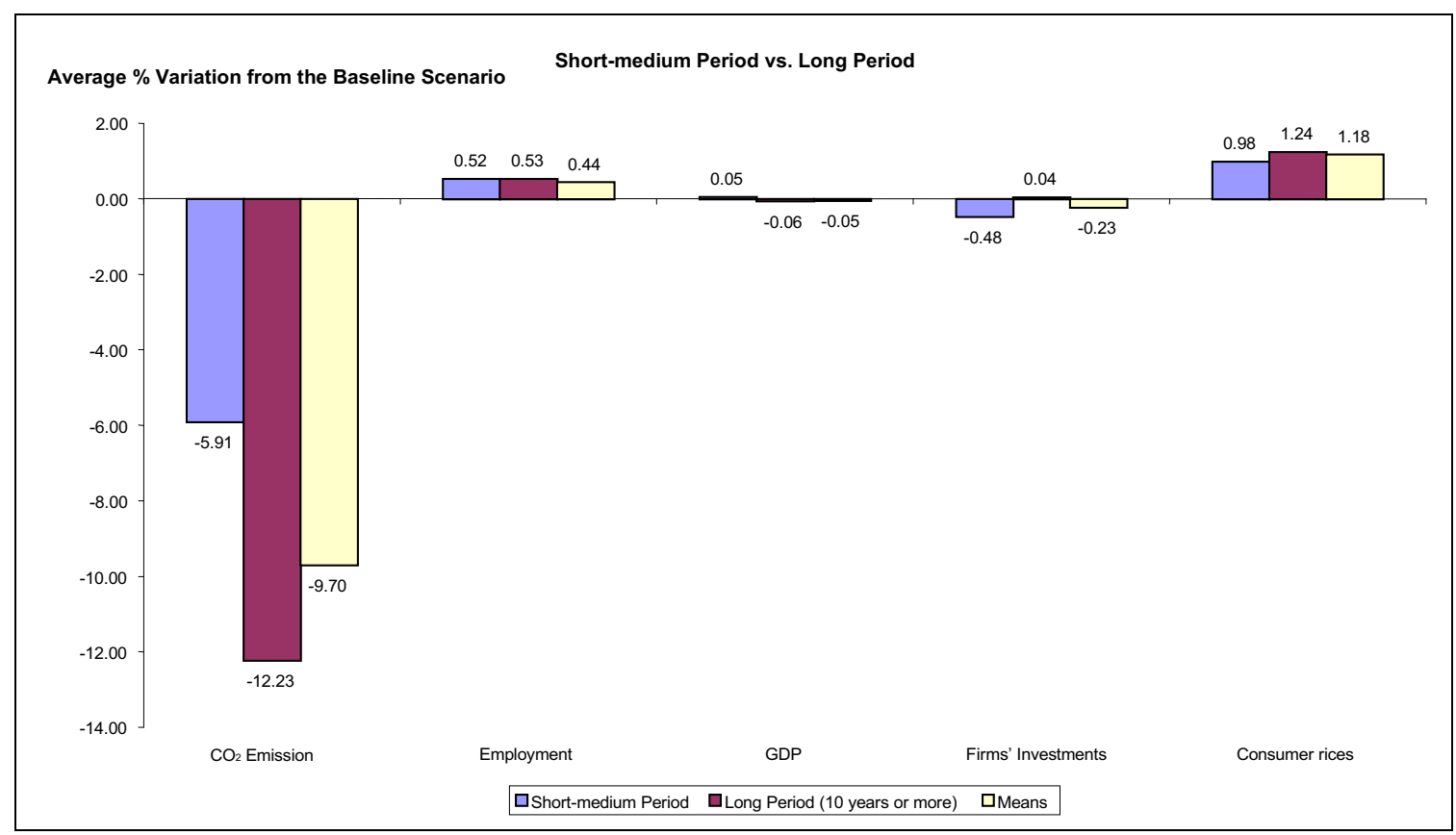

Figure 3 - Short/medium-term vs. Long-term

From the results (Figure 4) we derive that the effects of the taxes are similar for both groups. A difference in the $\mathrm{CO}_{2}$ emission reductions (a smaller reduction with the EC tax) and a difference in the variation in investments can also be seen. The EC tax therefore seems to be less ambitious than the other types of taxation, especially weakening the investment process, while the expected result of ETR is a stimulation of technological progress, which is strictly tied to the investment rate. The general tendencies remain relatively unchanged; we always see a positive variation in employment, a nearly null result for GDP and similar consumer prices variations for both groups.

Although taxation represents an initial and important step in ETR, recycling the tax revenues is undoubtedly just as important. A large number of studies has focussed on the effects of implementing revenue recycling on labour costs. In fact, lowering social security contributions (SSC) is the most common form of recycling. This is justified

\footnotetext{
5 The "other" tax forms are: $\mathrm{CO}_{2}$ tax, based on the emission of $\mathrm{CO}_{2}$ gasses; energy tax, based on the use of energy; and tax types including mixed taxes, tax on fossil fuels and electricity, fossil or Btu tax, tax on fossil fuels and electricity.

${ }^{6}$ Barker and Köhler (1998) note that the EC tax is probably inefficient on the economic side, since it focuses mainly on the introduction of the taxes rather than on how to recycle the obtained revenues.
} 
by the high level of unemployment in Europe (Bosquet, 2000). Moreover, since lowwage labour is a good substitute for energy, reducing labour taxes could induce industries to hire more workers.

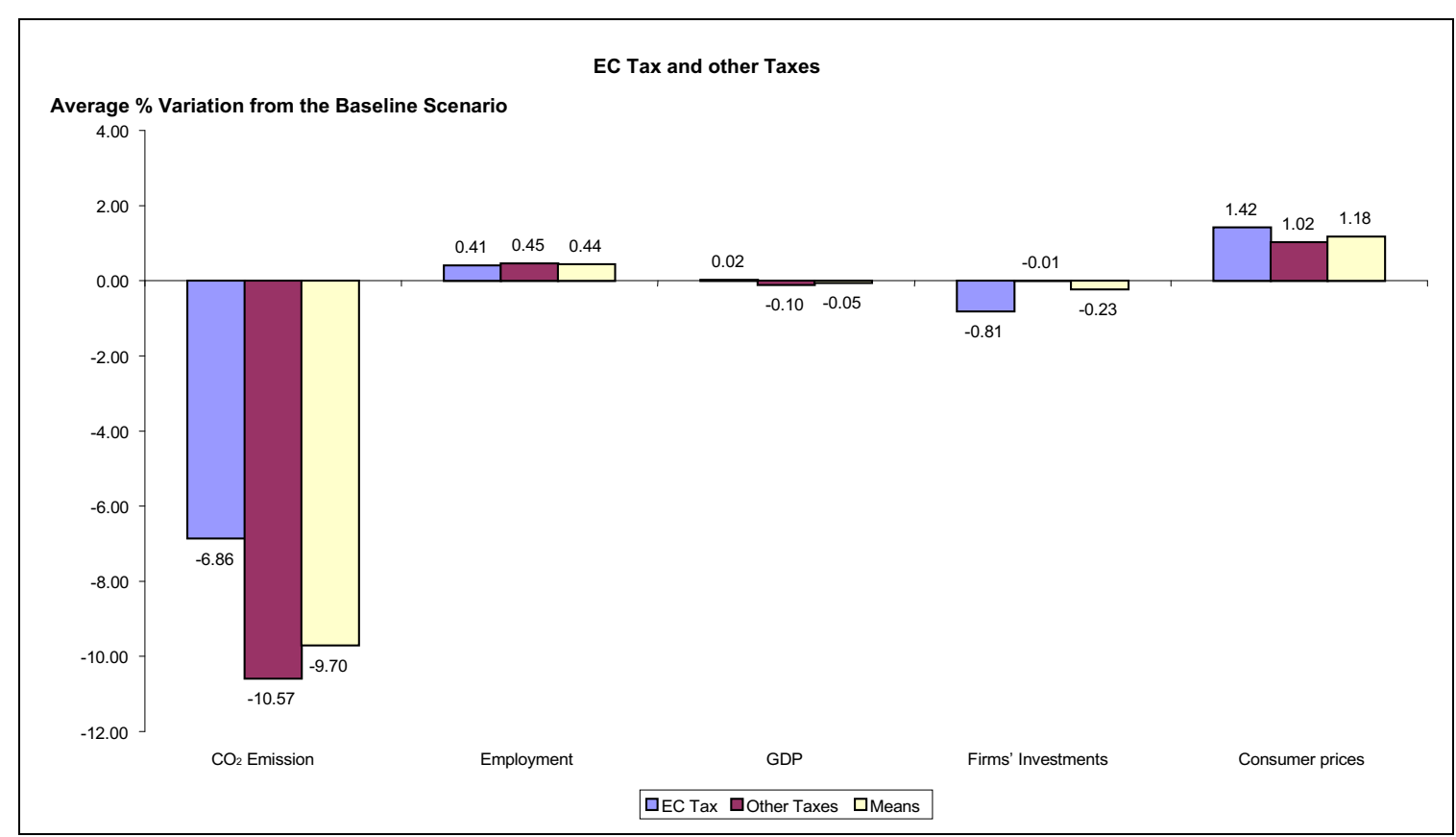

Figure 4 - The EC tax and the other taxes

An innovative form of recycling would be the use of the revenues to partially finance the pension system (Barker et al., 1993). In their study, Barker et al. also demonstrate that employment and wages grow more with SSC recycling than without it.

Figure 5 shows that there is little difference between the economic results obtained with SSC recycling and those obtained with the other types of recycling. While there is a noteworthy difference in results on the environmental side, on the economic side we see that in the case of SSC recycling there is a slightly greater positive variation for employment - probably induced by the lower labour cost -, although the degree of variation remains modest.

Finally, the last comparison is aimed at discovering whether for the available studies there are considerable differences between those published in journals (and in books) and those published as working papers (or reports). The objective is to verify whether the papers selected to appear in refereed journals (or in books) display better results (see Figure 6). 


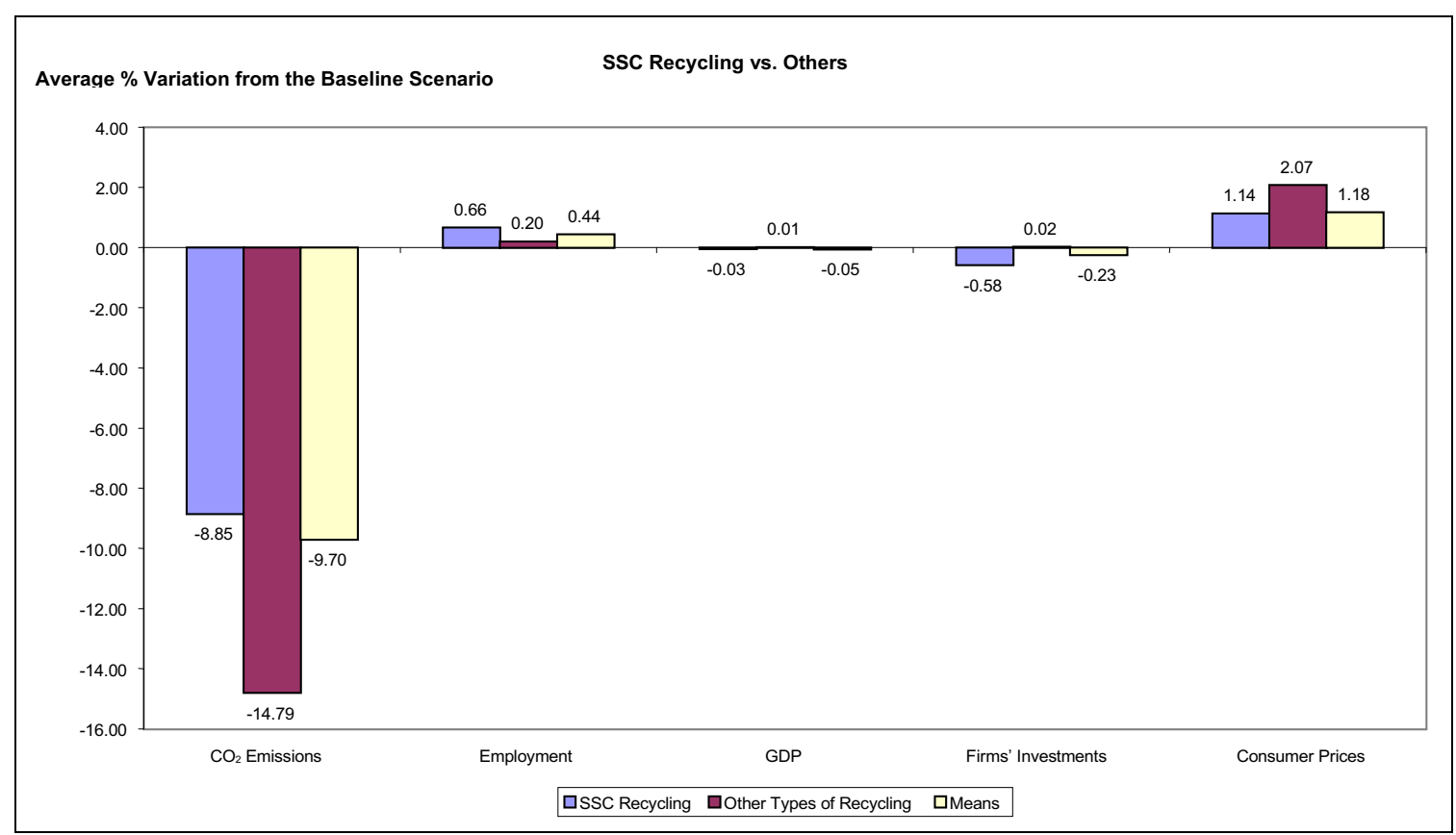

Figure 5 - Social security contributions (SSC) recycling and the other forms of recycling

In Figure 6, several interesting things can be observed. $\mathrm{CO}_{2}$ reductions shown in studies published in official journals are slightly larger, while the decrease in investments is smaller. Moreover, for the other variables the results are slightly better in the journal articles.

From an examination of these studies, we can conclude that the results of refereed and officially published studies seem, on average, to offer a moderately better performance. This does, however, not provide valid and convincing evidence that publication choices by authors are based on the achievement of positive ETR results.

In order to systematically verify some of the above conclusions, we will carry out a more profound meta-analytical statistical treatment of the database in the next section. These experiments are aimed at identifying statistically significant factors that might influence the economic and environmental results of ETR. 


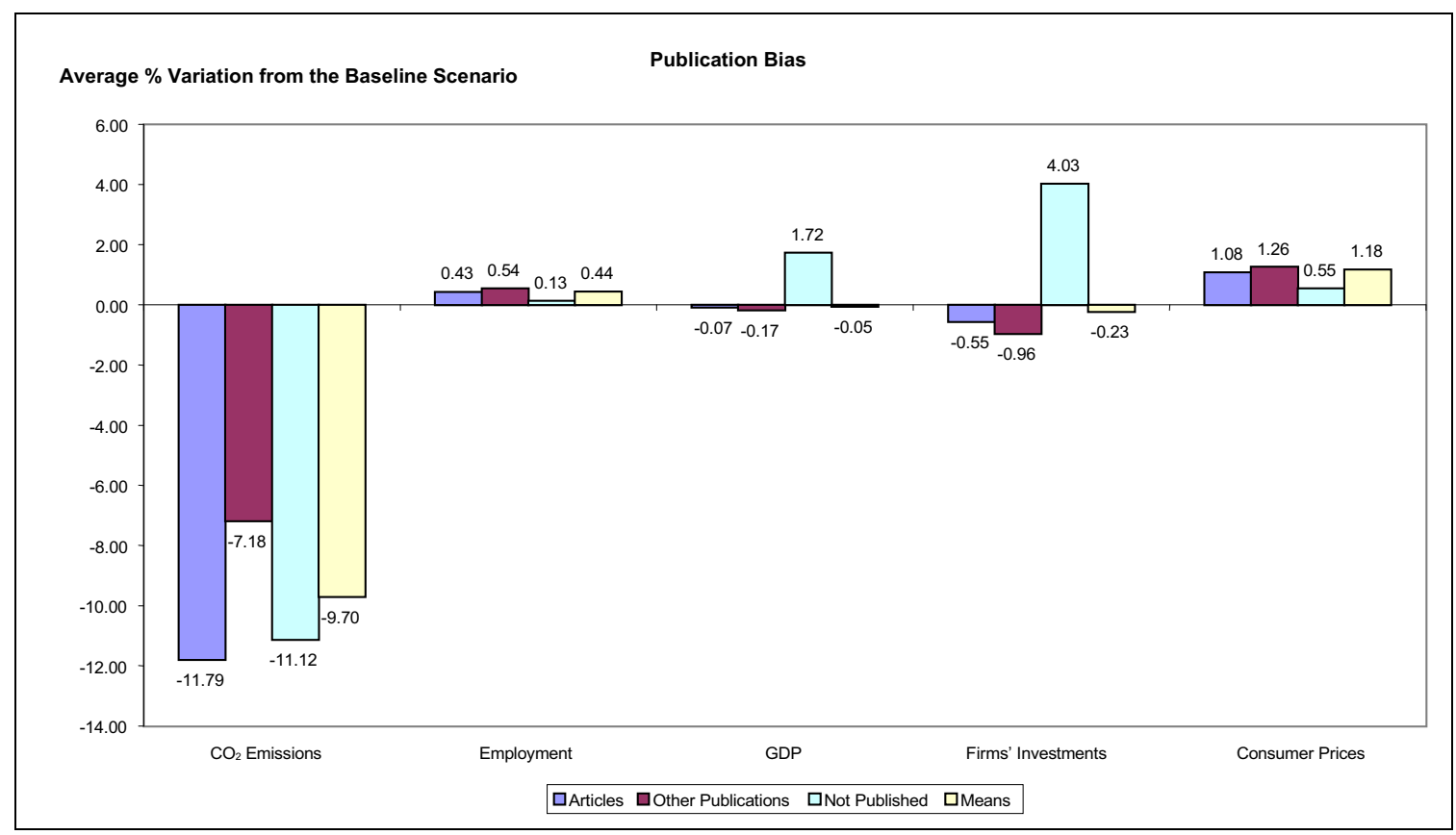

Figure 6 - Publication bias

\section{Statistical Analysis}

From the discussion in the previous sections it appears that there is neither a clear theoretical nor clear empirical evidence on the double dividend phenomenon. In this section, the data at hand are used in a meta-statistical analysis to test whether the use of different types of taxes, economic models and other moderator variables yield different simulation results. If this were true, policy recommendations would also be different. The analysis starts (in Subsection 4.1) with a discussion of statistical dependence, which may influence the estimations.

\subsection{The problem of inter-study and infra-study variability}

The data set contains simulation results from different studies; on average there are three simulations per study. In Multivariate Analysis of Variance (MANOVA), the most basic assumption is that of independence of observations. One possible source of dependence of observations is the simple fact that they originate from the same study; similar simulation techniques, assumptions or inputs may lead to similar simulation results. The first step in our analysis should, therefore, be to determine whether there is a dependence of observation in simulations belonging to the same study. There is, however, no single test that detects dependency with absolute certainty. One might consider grouping together observations, in which dependency is expected, by using, 
for example, study means. In this case, however, the number of observations is not sufficient for this strategy to provide significant results (in some cases, the number of observations per cell would be too low).

The simplest way to answer the above question is to calculate the study means and the different variances for simulations and study means results (the results grouped together are identified by the * superscript).

Table 2 - Overall and study-mean average and variance

\begin{tabular}{lrrrrrrrrrr}
\hline & $\mathrm{CO}_{2}$ & \multicolumn{1}{c}{$\mathrm{CO}_{2}{ }^{*}$} & \multicolumn{1}{c}{ Emp } & $\mathrm{Emp}^{*}$ & \multicolumn{1}{c}{$\mathrm{GDP}$} & $\mathrm{GDP}^{*}$ & \multicolumn{1}{c}{ Inv } & Inv $^{*}$ & Prices & Prices \\
\hline Valid & 129 & 32 & 94 & 27 & 171 & 56 & 94 & 28 & 80 & 31 \\
Missing & 62 & 159 & 97 & 164 & 20 & 135 & 97 & 163 & 111 & 160 \\
Mean & -9.91 & -9.70 & 0.64 & 0.44 & -.066 & -0.03 & -0.08 & -0.23 & 1.46 & 1.18 \\
Variance & 89.62 & 111.95 & 1.77 & 0.38 & 1.24 & 1.70 & 6.98 & 7.90 & 2.17 & 1.40 \\
\hline
\end{tabular}

For three of the five considered variables we observe higher inter-study-variances, suggesting that the between-studies variation may be larger than the within-studies variation (so that for these variables no severe dependency problems are expected), while in the remaining cases the opposite result is found ${ }^{7}$. We therefore cannot ignore the possibility of dependence of observations, but we also cannot exclude the entire simulations database a priori in favour of the study means (i.e. use study means rather than individual simulation results in the analysis). Instead, we will use a lower level of significance in the analysis.

In the following subsections separate analyses will be conducted for different combinations of variables. Since not all studies report uniformly results for the same set of variables (e.g., $\mathrm{CO}_{2}$ emissions, employment and GDP results), we are faced with missing variables which do not allow us to include all variables in a single

\footnotetext{
${ }^{7}$ The idea rests on the following reasoning. When two rather similar (or almost identical) simulation results (from one study) are combined, the overall mean will change. When these two values are close to the overall mean, but the average (squared) deviation from the mean of the other values is relatively large, the relative change in the average squared distance to the mean is normally lower than the relative change in the number of cases. As a result, the variance will increase. If the average (squared) deviation from the mean of the other values is relatively low, the relative change (decrease) in the average squared distance to the mean may be larger than the relative change in the number of cases; the variance will then decrease. Thus, when the between-studies variation is relatively large (larger than the variance of the elements which are to be combined), then combining related cases will increase the overall variance. When the variance of the elements to be combined is higher than the overall variance (i.e. the two elements show a higher variance and may not be correlated), the overall variance will decrease when the elements are combined. This argument holds when the elements which are expected to be dependent are close to the overall mean; clearly, this is not an official test for dependence.
} 
analysis. Because the sample changes thus with each part of our analysis, it is not possible to employ the same categories of variables in all analyses.

\subsection{Analysing relationships between the variables}

Since only a few cases are available that include $\mathrm{CO}_{2}$, employment and GDP results (at least too low for a statistical analysis), our quantitative experiments must be conducted pair-wise, for example, for the pair $\mathrm{CO}_{2}$-employment. Given our chosen definition of double dividend (see Section 2), we will mainly look at $\mathrm{CO}_{2}$ and employment. The general model is:

$$
\mathbf{Y}_{\mathrm{i}, \mathrm{j}}=\mu+\alpha_{\mathrm{i}}+\beta_{\mathrm{j}}+\delta_{\mathrm{i}, \mathrm{j}}+\mathbf{e}_{\mathrm{i}, \mathrm{j}}
$$

where $\mathbf{Y}$ is the (vector of) effect size(s), $\mu$ is the vector of general means, $\alpha_{i}$ is the effect of the $i^{\text {th }}$ category of the variable $\alpha$ (e.g. tax type), $\beta_{\mathrm{j}}$ is the effect of the $\mathrm{j}^{\text {th }}$ category of variable $\beta$ (e.g. recycling). $\delta$ is the interaction between $\alpha$ and $\beta$, and $\mathbf{e}$ is an IID error term with 0 mean and constant variance. When there is, for example, no tax type effect $\left(\mathrm{H}_{0}: \alpha_{\mathrm{i}}=0\right)$, the model reduces to:

$$
\mathbf{Y}_{\mathrm{i}, \mathrm{j}}=\mu+\beta_{\mathrm{j}}+\delta_{\mathrm{i}, \mathrm{j}}+\mathbf{e}_{\mathrm{i}, \mathrm{j}}
$$

Since we have a vector of effects (effects on $\mathrm{CO}_{2}$ emissions and employment), a multivariate test is necessary to test the null hypothesis $\left(\mathrm{H}_{0}: \alpha_{\mathrm{i}}=0\right)$. An important effect is the interaction effect. When the interaction is disordinal, the effects of one treatment (variable) are positive for some level of the other treatment, and negative for other levels. In this case, the results cannot be interpreted (because effects do not only vary across treatment levels, but also in direction) (Hair et al., 1998).

First, we verify whether tax type and recycling are significant factors producing changes in $\mathrm{CO}_{2}$ emissions and employment. Tests for the significance of the factors offer a positive result for recycling only, as shown in Table $3^{8,9}$. The interaction effect is insignificant at a 95\% confidence level. Although one could argue that the effect is significant at $90 \%$ confidence, so that one has to reconsider the model, it was

\footnotetext{
${ }^{8}$ Group "tax type2" was used in this analysis; see the Appendix.

${ }^{9}$ Various multivariate tests are available. Pillai's trace was chosen, because "evidence suggests that Pillai's criterion is more robust, and should be used if sample size decreases, unequal cell sizes appear, or homogeneity of covariances is violated" (Hair et al., 1998).
} 
mentioned above that due to the low number of observations and dependency issues, a higher confidence level is necessary. The test for the tax type yields an insignificant result, although significant results can be found for the tax type, if a different grouping of the data is used ${ }^{10}$.

Table 3 - Multivariate Tests: Pillai's Trace

\begin{tabular}{lccc}
\hline \multicolumn{1}{c}{ Effect } & Value & $\mathrm{F}$ & Significance \\
\hline Tax Type & 0.094 & 1.235 & 0.301 \\
Recycling & 0.375 & 5.763 & 0.000 \\
Tax*Recycling & 0.157 & 2.135 & 0.082 \\
\hline
\end{tabular}

Additional analyses, based only on tax type, provided also significant results; so it seems that the grouping we have chosen and the related analysis with recycling might conceal a significant relationship between the variables. The grouping of variables, therefore, introduces a bias into the results and reduces our chance of determining consistent results. More complete and heterogeneous studies would be needed to better assess the relationships between variables, since the current groupings heavily influence the results obtained.

From Table 3 we may conclude that "tax type" has no effect; i.e. different levels for the tax-type variable do not explain differences in the levels of $\mathrm{CO}_{2}$ emission and changes in employment. "Recycling" appears to have a significant effect. This effect is further analysed in Table 4. It seems that the effect of recycling is limited to employment only. $\mathrm{CO}_{2}$-levels are not dependent on the type of recycling. This is according to our prior expectation; recycling of (environmental) tax revenues was designed to reduce the cost of labour in order to stimulate the economy. Whether or not this is a positive effect will be analysed at a later stage. Again, with a different grouping, the tax type's results turn out to be significant, for both $\mathrm{CO}_{2}$ emission and employment.

\footnotetext{
${ }^{10}$ Different data groupings were sometimes necessary during our analysis, since the combination of different variables occasionally created groups containing too few cases for an analysis (because of missing results). In order to solve this problem, we sometimes categorised results according to different criteria. See the Appendix for the different groupings.
} 
Table 4 - Univariate F-tests

\begin{tabular}{clrr}
\hline \multicolumn{1}{c}{ Source } & Dependent Variable & \multicolumn{1}{c}{ F } & \multicolumn{1}{c}{ Sig. } \\
\hline Recycling & $\mathrm{CO}_{2}$ emissions & 1.131 & 0.331 \\
& Employment & 7.288 & 0.002 \\
Tax type $\times$ Recycling & $\mathrm{CO}_{2}$ emissions & 0.83 & 0.43 \\
& Employment & 4.46 & 0.01 \\
\hline
\end{tabular}

The univariate test shows that there is some interaction effect of recycling and tax type on employment. The multivariate test however, does not reject the nullhypothesis of no interaction effect. Since the main interest is the effect (of taxation and recycling) on both employment and $\mathrm{CO}_{2}$ emission, the multivariate test is used for a conclusive statement. The main conclusion that can be drawn from this analysis (see Tables 3 and 4) is that the combined use of a tax-and-recycle policy has a significant influence on the economic variables (the second dividend). Next, the direction of this effect can be determined by estimating regression parameters for each kind of tax and recycling considered (see Table 5).

Table 5-Parameter Estimates

\begin{tabular}{|c|c|c|c|c|}
\hline Dependent Variable & Variable & $\begin{array}{l}\text { Parameter } \\
\text { estimate }\end{array}$ & $\mathrm{t}$ & Significance \\
\hline \multirow[t]{5}{*}{$\mathrm{CO}_{2}$ Emissions } & Intercept & -9.000 & -1.208 & 0.233 \\
\hline & Tax Type $=\mathrm{CO}_{2}$ & -1.000 & -0.124 & 0.902 \\
\hline & Tax Type=Energy & 2.410 & 0.308 & 0.759 \\
\hline & Tax Type $=\mathrm{CO}_{2} \times$ Recycling $=\mathrm{SSC}$ & -10.853 & -1.272 & 0.209 \\
\hline & Tax Type $=$ Energy $\times$ Recycling $=$ SSC & -10.848 & -0.989 & 0.327 \\
\hline \multirow[t]{7}{*}{ Employment } & Intercept & 2.060 & 2.002 & 0.051 \\
\hline & Tax Type $=\mathrm{CO}_{2}$ & -1.753 & -1.577 & 0.121 \\
\hline & Tax Type=Energy & -1.986 & -1.840 & 0.072 \\
\hline & Recycling=LSTH & -0.260 & -0.498 & 0.62 \\
\hline & Recycling-SSC & -1.231 & -1.158 & 0.252 \\
\hline & Tax Type $=\mathrm{CO}_{2} \times$ Recycling $=\mathrm{SSC}$ & 3.487 & 2.960 & 0.005 \\
\hline & Tax Type $=$ Energy $\times$ Recycling $=$ SSC & 2.357 & 1.556 & 0.126 \\
\hline
\end{tabular}

The parameters for assessing the effects on the environment are insignificant. In the equation that explains the employment effect, we note that the intercept is significant at a $90 \%$-confidence level. The intercept can be interpreted as the direction of the generic effect of policy on employment. Combining $\mathrm{CO}_{2}$ taxes and social security recycling produces significantly positive results for employment. This could represent the mix we are searching for between environmental impact and economic balance.

A pairwise comparison of the discriminating factors (see Table 6) confirms that, in this case, there is no significant difference between tax types. Different groupings give 
different results for $\mathrm{CO}_{2}$ taxes, which appear to be significantly more effective than the others.

Regarding recycling, we note that intervention in social security contributions has a significantly better impact on employment than lump sum transfers. This result confirms the inefficiency of temporary measures like Lump Sum Transfers (LSTH). In fact, LSTH are "una-tantum" interventions that do not affect the economy as much as structural policies such as labour cost policy.

Table 6-Pairwise Comparisons

\begin{tabular}{lllcc}
\hline $\begin{array}{c}\text { Dependent } \\
\text { Variable }\end{array}$ & \multicolumn{1}{c}{$\begin{array}{c}\text { Tax } \\
\text { Type (I) }\end{array}$} & $\begin{array}{c}\text { Tax } \\
\text { Type (J) }\end{array}$ & $\begin{array}{c}\text { Mean } \\
\text { Difference (I-J) }\end{array}$ & Significance $^{*}$ \\
\hline $\mathrm{CO}_{2}$ emission & $\mathrm{CO}_{2}$ & Energy & -4.860 & 0.746 \\
& & Other & -7.874 & 0.183 \\
& Energy & Other & -3.014 & 1.000 \\
Employment & $\mathrm{CO}_{2}$ & Energy & 0.335 & 1.000 \\
& & Other & -0.473 & 1.000 \\
& Energy & Other & -0.808 & 0.874 \\
Dependent & \multirow{2}{*}{ Recycling (I) } & Recycling (J) & Mean & Significance \\
Variable & & & Difference (I-J) \\
Employment & LSTH & SSC & -1.484 & 0.010 \\
& & other & -0.767 & 0.383 \\
& SSC & other & 0.717 & 0.552 \\
\hline
\end{tabular}

"The null hypothesis is that the mean of group I is equal to the mean of group $\mathrm{J}$.

From these results, it is not clear that an environmental tax directly affects $\mathrm{CO}_{2}$ emissions or economic indicators. Recycling has a significant effect on employment. The direction of this effect will now be tested. It should be noted that incomplete data (or limited number of studies) prevent a complete analysis from being performed and do not allow us to draw conclusions on the nature of the relationships between these variables.

Analysing the isolated effect of the type of recycling on employment reconfirms that recycling revenues from environmental taxes to reduce social security contributions is economically beneficial. The analysis shows that recycling is a significant factor for both employment and Gross Domestic Product. It also shows that SSC recycling is especially significant for employment, with a positive value of the regression parameter $b$ (see Table 7). A pair-wise analysis on recycling shows that SSC recycling acts significantly better than almost all other parameters (such as Personal Income Taxes (PIT)). 
Table 7 - Parameter Estimates

\begin{tabular}{ccccc}
\hline $\begin{array}{c}\text { Dependent } \\
\text { variable }\end{array}$ & Variable & $\begin{array}{c}\text { Parameter } \\
\text { estimate }\end{array}$ & $\mathrm{t}$ & Significance \\
\hline Employment & -0.004 & -0.004 & -0.085 & 0.933 \\
& 0.008 & 0.008 & 0.142 & 0.887 \\
& -0.197 & -0.197 & -0.344 & 0.732 \\
& 1.304 & 1.304 & 2.841 & 0.006 \\
\hline
\end{tabular}

\subsection{Analysing the relationship between economic indicators and type of economic model used in the studies}

The different simulation studies use different economic models to determine the economic effects of ETR; general equilibrium and macroeconomic models are the most common models. Other models used are, for example, input-output and perfect equilibrium models; these models were not employed in a sufficient number of cases to be considered in separate groups. Multivariate analyses with employment and $\mathrm{CO}_{2}$ emission as dependent variables and "economic model" as treatment lead to the conclusion that the null hypothesis of no treatment effects is not rejected; the type of economic model does not explain differences in $\mathrm{CO}_{2}$ and employment effects of $\mathrm{ETR}^{11}$.

A multivariate analysis was also performed using GDP and employment as dependent variables. The results show that then the economic model is a significant factor in determining the results (Table 8).

Table 8 - Multivariate Tests: Pillai's Trace

\begin{tabular}{ccc}
\hline Effect & Value & Significance \\
\hline Economic model & 0.222 & 0.002 \\
\hline
\end{tabular}

In order to determine the effect of the type of economic modelling on the dependent variables, a separate testing was done. The results showed that a specific modelling approach has a significant influence on both GDP and employment (see Table 9).

Table 9 - Tests of Between-Subjects Effects

\begin{tabular}{clcc}
\hline Source & Dependent Variable & F & Significance \\
\hline Economic model & Employment & 3.866 & 0.025 \\
& GDP & 6.167 & 0.003 \\
\hline
\end{tabular}

\footnotetext{
${ }^{11}$ These results are not here presented to save space, but are available from the authors upon request.
} 
The type of economic model used therefore significantly affects both Gross Domestic Product and employment. But how does it influence their values? The regression results (not presented to save space) show that "general equilibrium models" have a positive impact on "employment", although this effect is only significant at a $90 \%$ level of significance. This may lead us to conclude that General Equilibrium (GE) models tend to produce positive results regarding employment and GDP. In order to confirm this, a pair-wise comparison (based on marginal means) was employed to compare models (see Table 10). The analysis confirms that GE and Macroeconomic models significantly differ from each other, since General Equilibrium models show more system-wide positive effects on the economy.

Table 10 - Pairwise Comparisons ${ }^{*}$

\begin{tabular}{lllcc}
\hline $\begin{array}{c}\text { Dependent } \\
\text { Variable }\end{array}$ & \multicolumn{1}{c}{$\begin{array}{c}\text { Economic } \\
\text { Model (I) }\end{array}$} & $\begin{array}{c}\text { Economic } \\
\text { Model (J) }\end{array}$ & $\begin{array}{c}\text { Mean } \\
\text { Difference (I-J) }\end{array}$ & Significance \\
\hline Employment & General Equilibrium & Macroeconomic & 0.835 & 0.042 \\
& & Other & 1.304 & 0.247 \\
\multirow{4}{*}{ GDP } & Macroeconomic & other & 0.468 & 1.000 \\
& General Equilibrium & Macroeconomic & 0.757 & 0.002 \\
& & other & 0.357 & 1.000 \\
& Macroeconomic & other & -0.401 & 1.000 \\
\hline
\end{tabular}

${ }^{*}$ The null hypothesis that the mean of group I is equal to the mean of group J.

Given the significant effect of the model type on the GDP result, a multivariate analysis with $\mathrm{CO}_{2}$ emission and GDP was tried out, using tax-type and economic models as treatments. Table 11 shows that both treatment effects are significant, and that the interaction effect is barely significant at a $95 \%$ confidence and insignificant at higher confidence levels. Changing the classification of tax-type ${ }^{12}$, however, renders the "tax-type" insignificant; the same observation was already made in Subsection 4.2. The effect of treatment "economic model" is, however, unaffected (these tests are not reported to save space).

Table 11 - Multivariate Tests: Pillai's Trace

\begin{tabular}{lll}
\hline Effect & Value & Sig. \\
\hline Tax type & 0.219 & 0.001 \\
Economic model & 0.125 & 0.011 \\
Tax type * Economic model & 0.121 & 0.050 \\
\hline
\end{tabular}

\footnotetext{
${ }^{12}$ Group "tax type3" was used for this supplementary analysis; see the Appendix.
} 
Although we may conclude from Table 11 that there are significant treatment effects, our regression analysis is inconclusive about the direction of the effect; the parameters are not significant. When we repeat the analysis ${ }^{13}$ with $\mathrm{CO}_{2}$-emissions and GDP as dependent variables and tax-type and tax-recycling as treatment, the multivariate tests do not reject the null hypothesis of no treatment effects ${ }^{14}$. It thus appears that the definition of the double-dividend itself may lead to different conclusions on the desirability of ETR.

A supplementary analysis was carried out to verify the idea that short and medium term simulations could lead to different conclusions on the performance of ETR than long run studies (as was also investigated in Figure 3).

Effects on $\mathrm{CO}_{2}$ emissions and employment were considered, while time period and economic model ${ }^{15}$ were used as independent variables. The time period variable distinguished between short-medium run studies (attributed to simulations on a time period shorter than 10 years) and long run studies.

Results from the analysis show (see Table 12) that neither time period or economic model are significant in the model.

Table 12 - Multivariate Tests: Pillai's Trace

\begin{tabular}{lcc}
\hline \multicolumn{1}{c}{ Effect } & \multicolumn{2}{c}{ Value } \\
\hline Time period & 0.039 & 0.725 \\
Economic model & 0.016 & 0.654 \\
Time period $\times$ Economic model & 0.068 & 0.167 \\
\hline
\end{tabular}

Finally, univariate tests appeared to confirm these results. The observed difference in the $\mathrm{CO}_{2}$ emissions in Figure 3 is apparently not sufficiently large to lead to a rejection of the hypothesis that there is no effect of the study period on ETR results. For the economic variable (employment), this was to be expected, given the difference observed in Figure 3.

\footnotetext{
${ }^{13}$ Recycling group "recycling2" was used in this experiment.

${ }^{14}$ The significance level for (Pillai's) test statistic for the "recycling effect" is 0.03 . Taking into account that a high significance level is needed due to the problems described in Subsection 4.1, this effect was not further analyzed.

${ }^{15}$ Classification "Econ.Mod.2" was used for this analysis.
} 


\section{Conclusions}

In this paper we have offered a meta-analysis approach to (simulation) studies on environmental tax reform. The main focus was on investigating differences between sub-groups of studies and on finding statistical evidence about factors that could influence the environmental and economic performance of ETR.

We found that differences exist in various cases. Using "employment" for the definition of the double dividend, we find that the total effect of a tax-and-recycle policy has a significant influence on the economic variables (the second dividend). This effect is not found however, using "GDP" rather than employment. In a separate analysis (using "employment to define the second dividend), no significant influence of the variable "economic model" was found. Such an effect is found, however, when GDP is used to define the second dividend, although the direction of the effect is unclear.

Although these results all clearly suggest that "tax-type", "recycling-policy" and "economic model" are all of influence on the chance a double dividend can actually be obtained, the results are not entirely conclusive in the sense that we can unambiguously predict what combination of policies and models will lead to a higher double dividend. Moreover, the exact definition of the double dividend also (partly) determines the outcome.

These findings should be taken into consideration when considering the application of ETR. When simulation study results are used in the preparation of ETR, a focus on, for example, a single economic model or a recycling policy may lead to an overoptimistic or over-pessimistic view on the performance of ETR. The usual formulation of ETR, with a carbon/energy tax recycled through SSC reductions, continues to be a valid model, which could produce the above-mentioned double dividend (a better environment and more jobs). But it needs to be properly tested against different model specifications.

Further research might be directed towards investigating the effects of the type of economic model used in the simulations on both the environmental and the economic results obtained (for example, the effect of the EC tax in a general equilibrium model). A more complete set of studies would surely improve the robustness of the statistical tests and would no longer force us to use different grouping criteria for variables 
depending on the amount of available data. But clearly, this research synthesis shows that the design of the simulation studies itself influences the results, and this finding cannot be ignored in the design of ETR.

\section{Acknowledgements}

We would like to thank Benoît Bosquet for making available the data used in his study (Bosquet, 2000).

\section{References}

Barker T. (1997). "Taxing pollution instead of jobs: towards more employment without more inflation through fiscal reform in the UK" in $\mathrm{O}^{\prime}$ Riordan T. (Ed.), Ecotaxation, Earthscan, London, 1997, pp. 163-200.

Barker T., S. Baylis, P. Madsen (1993). "A UK Carbon/Energy Tax. The Macroeconomic Effects". Energy Policy 21, pp. 296-308.

Barker T., J. Köhler (1998). "Equity and Ecotax Reform in the EU: Achieving a 10 per cent Reduction in $\mathrm{CO}_{2}$ Emissions Using Excise Duties". Fiscal Studies 19 (4), pp. 375-402.

Bergh, J.C.J.M. van den, K.J. Button, P. Nijkamp and G.C. Pepping (1997), Metaanalysis in Environmental Economics, Dordrecht: Kluwer Academic Publishers.

Bosquet B. (2000). "Environmental Tax Reform: Does It Work? A Survey of the Empirical Evidence". Ecological Economics 34, pp. 19-32.

Bosquet B. (2001). "The Role of Natural Resources in Fundamental Tax Reform: Theory, Practice and Prospects". Ph.D. dissertation. University of Maryland, College Park.

Bossier F., T. Bréchet (1995). "A Fiscal Reform for Increasing Employment and Mitigating $\mathrm{CO}_{2}$ Emissions in Europe". Energy Policy 23 (9), pp. 789-798.

Bovenberg A.L., F. van der Ploeg (1993). "Green Policies in a Small Open Economy”. Discussion paper n. 785. Centre for Economic Policy Research, London.

Carraro C., M. Galeotti, M. Gallo, (1996). "Environmental Taxation and Unemployment: Some Evidence on the 'Double Dividend Hypothesis' in Europe". Journal of Public Economics 62, pp. 141-181.

European Commission (1995). "Amended Proposal for a Council Directive Introducing a Tax on Carbon Dioxide Emissions and Energy", Brussels.

European Commission (1997a). "Proposal for a Council Directive Restructuring the Community Framework for the Taxation of Energy Products", Brussels.

European Commission (1997b). "Presentation of the New Community System for the Taxation of Energy Products", Brussels.

Gee D. (1997). 'Economic Tax Reform in Europe: Opportunities and Obstacles in O' Riordan T. (Ed.), Ecotaxation, Earthscan, London, 1997, pp. 81-105.

Hair, J.F., R.E. Anderson, R.L. Tatham and W.C. Black (1998), Multivariate data analysis, New Jersey: Prentice Hall 
Jansen H., G. Klaassen (2000). "Economic Impacts of the 1997 EU Energy Tax: Simulations with Three EU-Wide Models". Environmental and Resource Economics 15, pp. 179-197.

Kuper G. (1996). "The Effects of Energy Taxes on Productivity and Employment: The Case of the Netherlands". Resource and Energy Economics 18, pp. 137-159.

Mabey N., J. Nixon (1997). "Are Environmental Taxes a Free Lunch? Issues in Modelling the Macroeconomic Effects of Carbon Taxes". Energy Economics 19, pp. 29-56.

Mooij R.A. de, A.L. Bovenberg (1998). "Environmental Taxes, International Capital Mobility and Inefficient Tax Systems: Tax Burden vs. Tax Shifting”. International Tax and Public Finance 5, pp. 7-39.

Morris G.E., T. Révész, E. Zalai, J. Fucskó (1999). “Integrating Environmental Taxes on Local Air Pollutants with Fiscal Reform in Hungary: Simulations with a Computable General Equilibrium Model". Environment and Development Economics 4, pp. 537-564.

Wendner R. (2001). "An Applied Dynamic General Equilibrium Model of Environmental Tax Reforms and Pension Policy". Journal of Policy Modeling 23, pp. 25-50.

Appendix - Grouping details

Table A - Tax Type grouping

\begin{tabular}{lcccc}
\hline TAX TYPE & $\mathrm{CO}_{2}$ & EC Tax & Energy & Other \\
\hline Tax type & $\mathrm{X}$ & $\mathrm{X}$ & $\mathrm{X}$ & $\mathrm{X}$ \\
Tax type2 & $\mathrm{X}$ & & $\mathrm{X}$ & $\mathrm{X}$ \\
Tax type3 & $\mathrm{X}$ & $\mathrm{X}$ & & $\mathrm{X}$ \\
\hline
\end{tabular}

$\mathrm{CO}_{2}$ : tax based on the emission of $\mathrm{CO}_{2}$ gasses

EC Tax: tax proposed by the European Community

Energy: tax based on the use of energy products

Other: comprises other types of tax (mixed taxes, tax on fossil fuels and electricity, fossil or Btu tax, tax on fossil fuels and electricity, escalator). Also comprises EC Tax in the second group and Energy Tax in the third group.

Table B - Recycling grouping

\begin{tabular}{lrrrrrr}
\hline RECYCLING & CPT & LSTH & PIT & SSC & VAT & Other \\
\hline Recycling & $\mathrm{X}$ & $\mathrm{X}$ & $\mathrm{X}$ & $\mathrm{X}$ & $\mathrm{X}$ & $\mathrm{X}$ \\
Recycling2 & & $\mathrm{X}$ & $\mathrm{X}$ & $\mathrm{X}$ & & $\mathrm{X}$ \\
\hline
\end{tabular}

SSC: social security contributions

PIT: personal income taxes

LSTH: lump sum transfers to households/industries

CPT: interventions in corporate profit taxes

VAT: value added tax

Other: comprises other types of recycling (mixed strategies, no recycling, other labor/capital taxes, refunds to industries, payroll taxes, pension system). Also comprises CPT and VAT recycling in the second group. 
Table C-Economic model grouping

\begin{tabular}{lrcc}
\hline ECON. MODEL & GE & M & Other \\
\hline Econ.Mod. & $\mathrm{X}$ & $\mathrm{X}$ & $\mathrm{X}$ \\
Econ.Mod.2 & $\mathrm{X}$ & & $\mathrm{X}$ \\
\hline
\end{tabular}

GE: General Equilibrium model

M: Macroeconomic model

Other: comprises other types of models (mixed models, input-output models, putty clay model, engineering model, perfect equilibrium, undefined models). Also comprises macroeconomic models in the second group. 